\title{
Comprehensive Review
}

\section{The Current State of Endoscopic Disc Surgery: Review of Controlled Studies Comparing Full- Endoscopic Procedures for Disc Herniations to Standard Procedures}

Christof Birkenmaier, MD1, Martin Komp, MD², Hansjörg F. Leu, MD, PD³,

Bernd Wegener, MD'1, and Sebastian Ruetten, MD, PD²

From: ${ }^{1}$ Department of Orthopaedics, University of Munich (LMU), Grosshadern Campus,Munich, Germany; 2Department of Spine Surgery and Pain Therapy, Center for Orthopaedics and Traumatology,

St. Anna-Hospital Herne, University of Witten/Herdecke, Herne, Germany; and 3The Bethania Spine Base, Bethania Hospital, Zurich, Switzerland

For the International Society for Minimal Intervention in Spinal Surgery (ISMISS)

Address Correspondence: Christof Birkenmaier, MD Department of Orthopaedics University of Munich (LMU)

Grosshadern Campus Marchioninistr. 15

81377 Munich, Germany

E-mail: doctor-b@web.de

Disclaimer: T. Some aspects of this data have been presented at the $3 \mathrm{~d}$ WCMISST, Salvador de Bahia, Brazil (18.-18.8.2012) and at the 31st International

Course for Percutaneous

Endoscopic Spinal Surgery and Complementary Minimal Invasive Techniques in Zurich, Switzerland (24.-25.1.2013). Conflict of interest: None.

Manuscript received: 02-27-2013 Accepted for publication: 03-29-2013

Free full manuscript: www.painphysicianjournal.com
Background: Neuropathic pain originating from spinal disc herniations is a very common problem. The majority of disc surgeries are performed to alleviate this pain once conservative measures and targeted injections have failed. Endoscopic spinal surgery is increasingly popular because it minimizes access trauma and hastens recovery from the intervention. This clinically oriented review evaluates controlled studies that investigate the clinical results and the complications of full-endoscopic lumbar and cervical procedures for symptomatic disc herniations in comparison to a microsurgical standard procedure. This review focuses exclusively on modern, full-endoscopic disc surgery irrespective of the specific access technique (e.g., interlaminar vs. transforaminal) and irrespective of the spinal region.

Study Design: Comprehensive review of the literature.

Objective: To assess the clinical outcomes and complication rates of full-endoscopic disc surgery compared to the microsurgical standard procedures.

Methods: A PubMed and Embase search was performed, considering entries up to January 2013. All 504 results were screened and categorized. Only 4 randomized controlled trials (RCTs) and one controlled studies (CS) could finally be considered for evaluation. All 5 manuscripts were meticulously analyzed with regards to randomization mode, inclusion/exclusion criteria, clinical results, and complication rates.

Results: Overall, the endoscopic techniques had shorter operating times, less blood loss, less operative site pain, and faster postoperative rehabilitation/shorter hospital stay/faster return to work than the microsurgical techniques. There were no significant differences in the main clinical outcome criteria between the endoscopic and the microsurgical techniques in any of the trials. All 5 studies had fewer complications with the endoscopic technique and this was statistically significant in 2 of the studies. One study showed a lower rate of revision surgeries requiring arthrodesis with the endoscopic technique.

Limitations: All 5 studies that could be considered originate from experienced investigators and all 4 RCTs came from one group. This limits the transferability of their results to surgeons less experienced in endoscopic disc surgery.

Conclusions: The studies show that full-endoscopic disc surgery can achieve the same clinical results in symptomatic cervical and lumbar disc herniations as the microsurgical standard techniques. This does not appear to come at the price of higher complication rates.

Key words: Neuropathic pain, disc herniation, cervical, lumbar, endoscopic, endoscopy, review

Pain Physician 2013; 16:335-344 
europathic pain caused by cervical or lumbar disc herniations is among the most common reasons for which patients seek specialist treatment. While guidelines in many countries stress the point that surgery should be reserved for cases with fresh motor deficits or cauda equina syndrome, the reality is that most disc surgeries, regardless of the technique used, are performed for nerve root pain (sciatica or cervicobrachialgia). It needs to be recognized that minimally invasive procedures with the goal to remove the herniation causing the problem are the logical next step after conservative measures and image-guided injection techniques have failed to provide adequate pain relief.

Endoscopic surgery attempts to bridge the gap between injection techniques and open surgery in as much as it attempts to perform the decompression required via the most minimized surgical approach possible, which is the placement of an instrument of just a few millimeters in diameter over the spinal needle that otherwise would have been used to perform a selective nerve root block or a different type of injection. Early on, there already had been indications for better outcomes with less invasivity (1). Endoscopic disc surgery was pioneered in the late 1980s and in the early 1990s, but for a number of reasons did not break into the mainstream of spinal therapies at that time (2-7).

Recent years have again seen growing interest in spinal endoscopy as well as the development of new anatomical approaches. The technically demanding field of spinal pain treatments is late in adopting this technology and this was made possible only by technical advances in the field of cameras, coaxial working sleeves, optics, video processing equipment, radiofrequency devices, and others. After all, joint arthroplasty had been firmly established for many years before spinal arthroplasty ever became a viable treatment option. Similarly, endoscopic techniques have become the gold standard for a large number of conditions in orthopedics, gynecology, anesthesiology, and surgery, while in spinal surgery they are still considered outsider procedures by many.

It therefore appears to be a suitable point in time to review the available studies on endoscopic disc surgery and to compare spinal endoscopy to the respective standard surgical procedures with regards to outcome and complications. This review is not a systematic review for a very practical reason. The scientific evidence for the superiority of microdiscectomy over conservative therapy or over standard open discectomy is still very weak, even though microdiscectomy represents the currently accepted gold standard as far as surgical treatments are concerned (8-11). A review of trials comparing newer procedures to microdiscectomy on the background of their relative levels of evidence would therefore inevitably come to the conclusion that there still is insufficient evidence to allow for any definitive conclusions.

The goal of this review is to investigate whether controlled studies exist that allow for the objective comparison of full-endoscopic spinal procedures to the respective gold standard procedures with regards to outcome and complications as the paramount clinical parameters on which treatment decisions are to be based. The scope of this review is limited to endoscopic disc surgery, primarily because the surgical treatment of symptomatic disc herniations is a very frequently performed spinal procedure. It also represents by far the most common spinal condition treated by means of endoscopy and for which established standard procedures, such as microdiscectomy or keyhole foraminotomy exist, against which endoscopic procedures can be compared. Papers primarily focusing on laser disc decompression (without targeted disc fragment extraction), which is sometimes performed under endoscopic visualization, were to be excluded from the search strategy. Different from Nellensteijn et al's (12) systematic review on transforaminal endoscopic disc surgery, studies on simple endoscopic decompression of the intradiscal space and/or indirect endoscopic decompression of the spinal canal by means of the "in-out-technique" were to be excluded. These techniques no longer represent the current standard of endoscopic disc surgery, which is the direct extraction of disc fragments from the epidural space/the foramina and the direct decompression of neural structures under full visual control.

Another fundamental difference from the recent review by Nellensteijn et al (12) is that our review is not limited to the transforaminal approach. While transforaminal was the first endoscopic approach for accessing the disc space and the ventral epidural space, interlaminar approaches have been established for the lumbar and for the cervical spine. A far lateral transforaminal approach has been described for the lumbar spine and an anterior transdiscal approach exists for the cervical spine. For the purpose of this review, we therefore must also define what we consider "truly endoscopic" in the context of spinal applications, since there is a longstanding confusion of termini technici with regards to spinal endoscopy. 
In the majority of other surgical specialties, endoscopy implies the use of a thin tubular optical and surgical device that is passed completely percutaneously by means of a stab incision. This is very different from using tissue dilators of increasing diameter in order to introduce tubular mini-retractor systems for creating a small, but nevertheless open access portal, sometimes even in combination with an operating microscope. Some experimental studies suggest that the use of tubular retractor systems is less traumatic than microdiscectomy on the basis of intraoperative electromyogram measurements and postoperative serum cytokine levels $(13,14)$. However, recent randomized controlled trials (RCTs) indicate that such tubular mini-retractor systems seem to offer no clinically relevant advantage over standard microdiscectomy and that they may have the potential of higher complication rates compared to either the microsurgical or the older open technique $(15,16)$.

The authors of this review distinguish the following 3 technical approaches to disc surgery as being separate entities.

\section{Microdiscectomy}

The use of a Caspar retractor or similar device and of an operating microscope to perform disc surgery through a small skin incision of only a few centimeters. In the lumbar spine, this is currently considered the gold standard.

\section{Tubular Discectomy}

The use of tissue dilators and of a tube system through a minimized incision of less than $2 \mathrm{~cm}$ together with an operating microscope. The most common example would be the Metrix tube system. The term "micro-endoscopic discectomy" is frequently used as a synonym. Constant irrigation is not generally used. Overall, this technique has much in common with the microsurgical approach but it reduces the access trauma by means of a blind transmuscular dilatation as compared to an open, visually controlled muscle dissection from the spinous process/lamina. The Destandeau endoscopic system is a special variation that also falls into this category. What differentiates this technique from the MetriX tube system is mainly the use of an endoscope/ monitor system and a blunt, single-step dilatation of the perispinal muscles.

\section{Endoscopic Disc Surgery}

This entails the use of a thin tubular device that contains the optical system and a working channel. It is introduced completely percutaneously through a stab incision. Usually, a spinal needle-guide wire technique is used to secure the controlled trajectory of a blunt trocar to the desired spinal region. The working sleeve is then passed over the trocar after removal of the guide wire. Visualization is always achieved by means of a connected video camera and monitor system. The terms "percutaneous endoscopic discectomy" or "fullendoscopic discectomy" have been used synonymously. A monoportal technique is standard and surgery is performed under constant saline irrigation.

For the purpose of this review, it was decided to focus exclusively on category 3 , truly endoscopic disc surgery, also known as "full-endoscopic disc surgery." These 3 surgical techniques are to be distinguished from pure epiduroscopic adhesiolysis, which has its own merits, but does not remove herniated disc material or other physical sources of direct nerve root compression (17-25).

\section{Methods}

PubMed and Embase database searches were performed using the following search strategy:

(endoscopic OR endoscopy) AND (disc OR discal OR disk OR diskal) AND (cervical OR lumbar OR lumbosacral) NOT laser. Database entries up to January 31, 2013, were considered. The returned results were screened and assigned to one of the following groups:

1. RCT

2. controlled studies (CS)

3. comparative studies

4. case series

5. case reports

6. review articles

7. technical articles, anatomical studies, reports on personal experience and letters

8. articles on laparoscopic spinal fusion

9. unrelated publications.

Only articles categorized as RCTs and CSs were considered for this review.

\section{Results}

Using the above search strategy, 504 references were retrieved. Twelve of these references were classified as $\operatorname{RCTs}(10,13,15,16,26-32)$ and another 15 were classified as CSs (33-47). The majority of references were categorized as case series (169), studies on tubular discectomy (113), articles on laparoscopic fusion surgery (38), review articles (79), or otherwise unrelated to the topic (95). 
Of the 12 RCTs, only 5 were using a true endoscopic technique as defined above and only 4 of these 5 trials had a standard procedure as a control group (29-32). Of the 16 CSs, only $6(36,37,39,44,47)$ were using a true endoscopic technique as defined above. Two of these latter 6 studies used an old intradiscal technique $(4,39)$, one compared endoscopic biopsy for spondylodiscitis to CT-guided biopsy (44) and 2 did not employ a control group as a standard technique $(36,47)$. The remaining controlled study had a retrospective, non-randomized study design and used intradiscal decompression in addition to direct visually controlled fragmentectomy (37), allowing for discussion of its results only with certain limitations. In summary, our search retrieved 4 RCTs that each compare a modern full-endoscopic technique for the treatment of cervical or lumbar disc herniations to an established standard microsurgical procedure. One additional CS can be considered only with clear limitations because of its retrospective, non-randomized study design and its particular surgical technique.

Established and standardized parameters for assessing clinical and radiological outcomes were used in all of these trials; the numbers of patients included are high enough to allow for clinically relevant conclusions. All 5 studies originate from very experienced groups of investigators, with all 4 RCTs having the same authors. The characteristics and the relevant results of these tri- als are displayed in Tables 1 and 2.

As can be seen from Table 1, the studies that were retrieved differ with regards to spinal region (cervical, lumbar), type of approach (transforaminal lumbar, interlaminar lumbar, interlaminar cervical, anterior transdiscal cervical), and type of herniation (recurrent, primary), as well as with regards to the respective comparison procedure. This rendered it unreasonable to use the source data of the individual trials as the basis for a meta-analysis. We therefore elected to analyze each RCT individually and to then discuss their common and their differing findings on the background of the pertaining limitations.

The first study (29) compared posterior endoscopic foraminotomy to microsurgical anterior decompression and fusion (ACDF; using a stand-alone poly-ether-etherketone [PEEK]-cage) for the treatment of lateral cervical disc herniations. This study was randomized and included 200 patients with a follow-up of 2 years and a follow-up rate of $88 \%$. The key findings were a reduced operating time ( 28 vs. 68 minutes on average) and a faster return to work (19 vs. 34 days) with the endoscopic technique. Clinical outcome and complication rates were not significantly different between the techniques.

The second study (30) compared endoscopic interlaminar and transforaminal lumbar discectomy to the conventional microsurgical technique (microd-

Table 1. Study Characteristics

\begin{tabular}{|c|c|c|c|c|c|c|c|c|c|c|c|c|}
\hline Study & type & $\begin{array}{l}\text { pro/ } \\
\text { retro }\end{array}$ & herniation type & $\begin{array}{l}\mathrm{n} \\
\text { total }\end{array}$ & m:f & $\begin{array}{l}\text { Randomiz. } \\
\text { mode }\end{array}$ & $\begin{array}{l}\text { endoscopic } \\
\text { procedure }\end{array}$ & $\mathbf{n}$ & $\begin{array}{l}\text { comparison } \\
\text { procedure }\end{array}$ & $\mathbf{n}$ & FU & $\begin{array}{l}\text { FU } \\
\text { Rate }\end{array}$ \\
\hline $\begin{array}{l}\text { Ruetten } \\
\text { et al, } 2008 \\
(20)\end{array}$ & RCT & pro & cervical lateral & 200 & $\begin{array}{l}68: \\
132\end{array}$ & $\begin{array}{l}\text { not blinded, } \\
\text { alternating } \\
\text { assignment }\end{array}$ & $\begin{array}{l}\text { endoscopic } \\
\text { posterior } \\
\text { foraminotomy }\end{array}$ & 100 & $\begin{array}{l}\text { microsurgical } \\
\text { ACDF (PEEK } \\
\text { cage, no plate) }\end{array}$ & 100 & $2 y$ & $88 \%$ \\
\hline $\begin{array}{l}\text { Ruetten } \\
\text { et al, } \\
2008(21)\end{array}$ & $\mathrm{RCT}$ & pro & $\begin{array}{l}\text { lumbar } \\
\text { (median, lateral, } \\
\text { extraforaminal) }\end{array}$ & 200 & $\begin{array}{l}84: \\
116\end{array}$ & $\begin{array}{l}\text { not blinded, } \\
\text { alternating } \\
\text { assignment }\end{array}$ & $\begin{array}{l}\text { endoscopic } \\
\text { interlaminar or } \\
\text { transforaminal } \\
\text { sequestrectomy }\end{array}$ & 100 & $\begin{array}{l}\text { microsurgical } \\
\text { sequestrectomy } \\
\text { (paramedian or } \\
\text { lateral) }\end{array}$ & 100 & $2 y$ & $89 \%$ \\
\hline $\begin{array}{l}\text { Ruetten } \\
\text { et al, } 2009 \\
(22)\end{array}$ & $\mathrm{RCT}$ & pro & lumbar recurrent & 100 & $56: 44$ & $\begin{array}{l}\text { not blinded, } \\
\text { alternating } \\
\text { assignment }\end{array}$ & $\begin{array}{l}\text { endoscopic } \\
\text { interlaminar or } \\
\text { transforaminal } \\
\text { sequestrectomy }\end{array}$ & 50 & $\begin{array}{l}\text { microsurgical } \\
\text { sequestrectomy } \\
\text { (paramedian } \\
\text { approach) }\end{array}$ & 50 & $2 y$ & $87 \%$ \\
\hline $\begin{array}{l}\text { Ruetten } \\
\text { et al, } 2009 \\
(23)\end{array}$ & RCT & pro & cervical & 120 & $43: 77$ & $\begin{array}{l}\text { balanced block } \\
\text { randomization, } \\
\text { not blinded }\end{array}$ & $\begin{array}{l}\text { anterior } \\
\text { transdiscal } \\
\text { endoscopic } \\
\text { decompression }\end{array}$ & 60 & $\begin{array}{l}\text { microsurgical } \\
\text { ACDF (PEEK } \\
\text { cage, no plate) }\end{array}$ & 60 & $2 y$ & $86 \%$ \\
\hline $\begin{array}{l}\text { Lee et al, } \\
2009(28)\end{array}$ & CS & retro & lumbar recurrent & 54 & $38: 16$ & not randomized & $\begin{array}{l}\text { endoscopic } \\
\text { transforaminal } \\
\text { sequestrectomy } \\
\text { and disc } \\
\text { decompression }\end{array}$ & 25 & $\begin{array}{l}\text { microsurgical } \\
\text { sequestrectomy } \\
\text { (paramedian } \\
\text { approach) }\end{array}$ & 29 & $\begin{array}{l}34 \\
\mathrm{~m}\end{array}$ & n.a. \\
\hline
\end{tabular}

Type specifies randomized controlled trial (RCT) vs. controlled study (CS), pro/retro specifies prospective vs. retrospective study design, $\mathrm{n}$ total = total number of patients studied in both groups, $\mathrm{m}: \mathrm{f}=$ male vs. female ratio, $\mathrm{FU}=$ time of follow up specified in years $(\mathrm{y})$ or months $(\mathrm{m}), \mathrm{FU}$ Rate specifies which percentage of patients were available at final follow up, ACDF $=$ anterior cervical decompression and fusion, PEEK $=$ poly-etherether-ketone, n.a. $=$ not applicable 


\begin{tabular}{|c|c|c|c|c|c|c|}
\hline 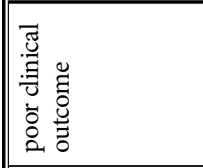 & $a$ & $\infty$ & 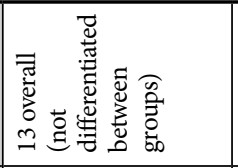 & 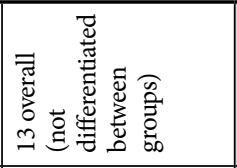 & 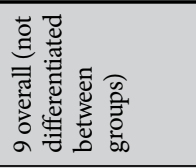 & 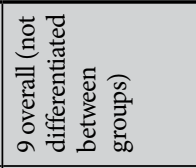 \\
\hline 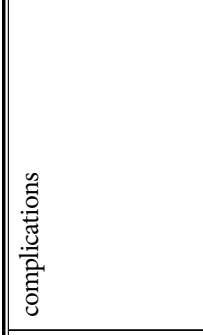 & 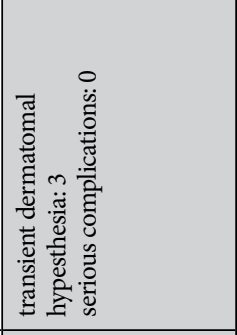 & 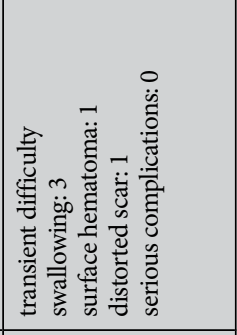 & 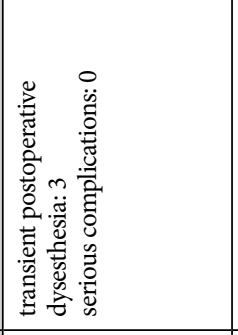 & 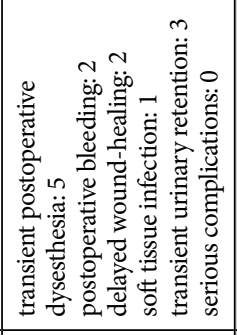 & 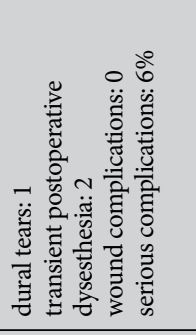 & 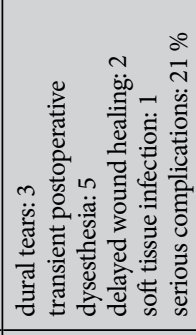 \\
\hline 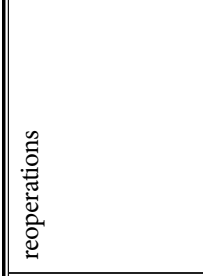 & 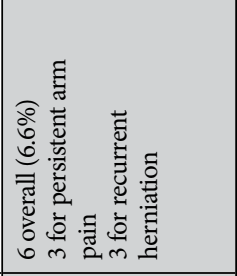 & 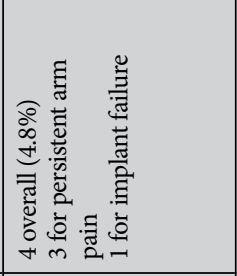 & 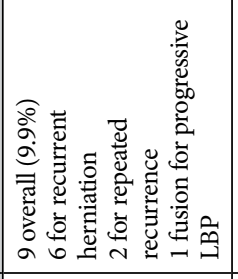 & 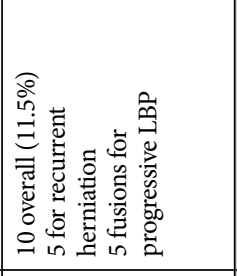 & 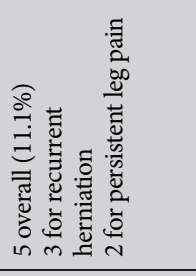 & 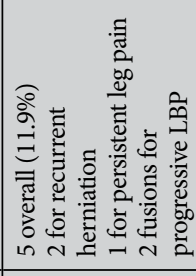 \\
\hline 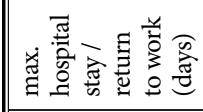 & \begin{tabular}{l}
2 \\
\multirow{7}{7}{} \\
\end{tabular} & 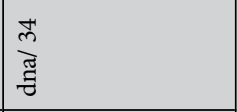 & 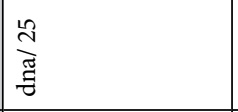 & \begin{tabular}{l}
$\frac{9}{1}$ \\
\multirow{3}{7}{} \\
\end{tabular} & 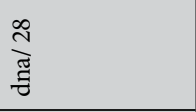 & 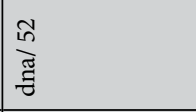 \\
\hline 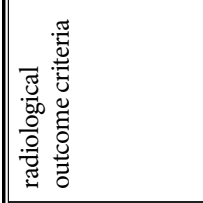 & 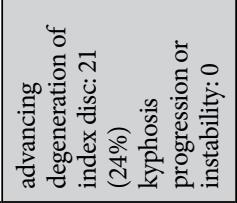 & 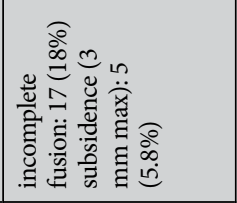 & 孚 & च & $\stackrel{\widetilde{g}}{\tilde{y}}$ & 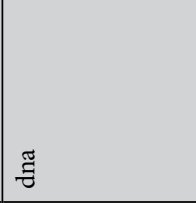 \\
\hline 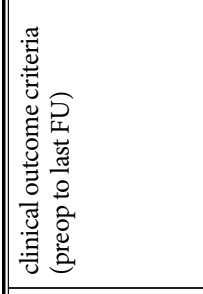 & 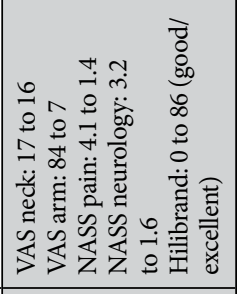 & 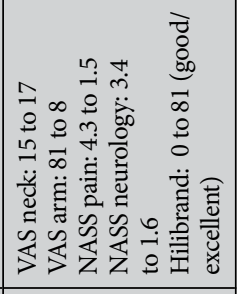 & 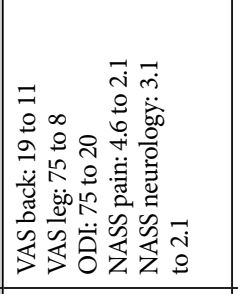 & 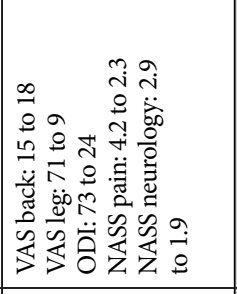 & 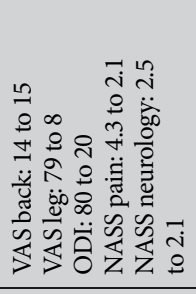 & 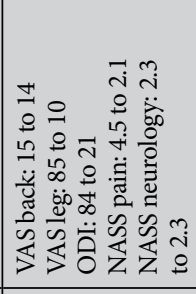 \\
\hline 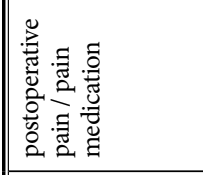 & 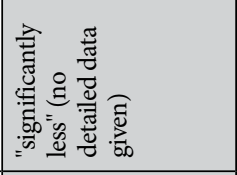 & & 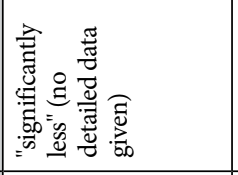 & & 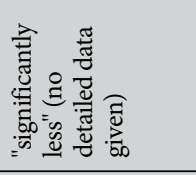 & \\
\hline 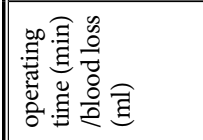 & 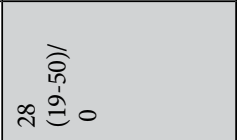 & 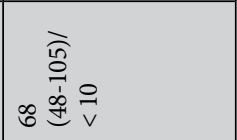 & 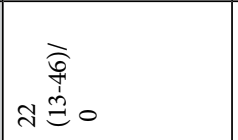 & 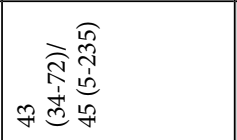 & 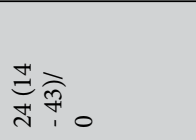 & 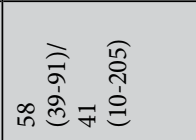 \\
\hline 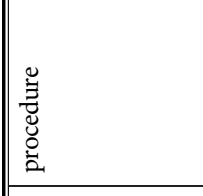 & 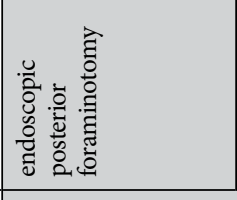 & 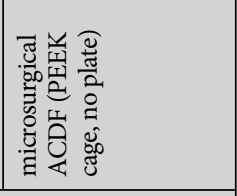 & 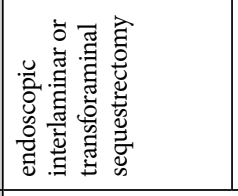 & 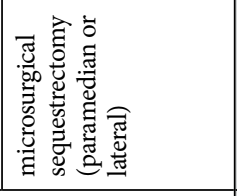 & 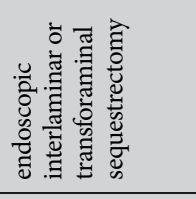 & 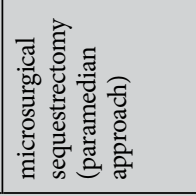 \\
\hline 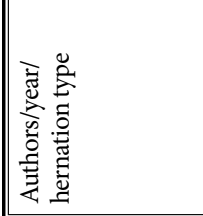 & \multicolumn{2}{|l|}{ 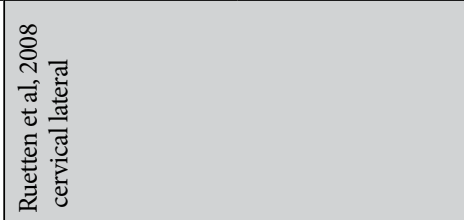 } & \multicolumn{2}{|l|}{ 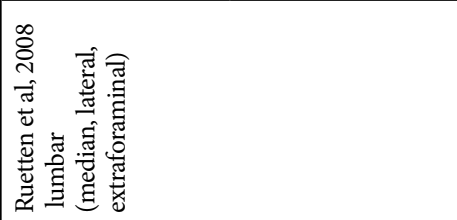 } & \multicolumn{2}{|l|}{ 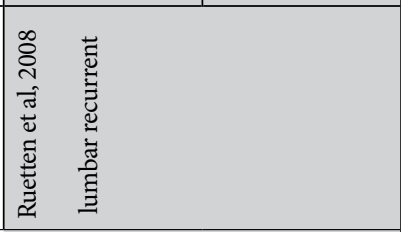 } \\
\hline
\end{tabular}




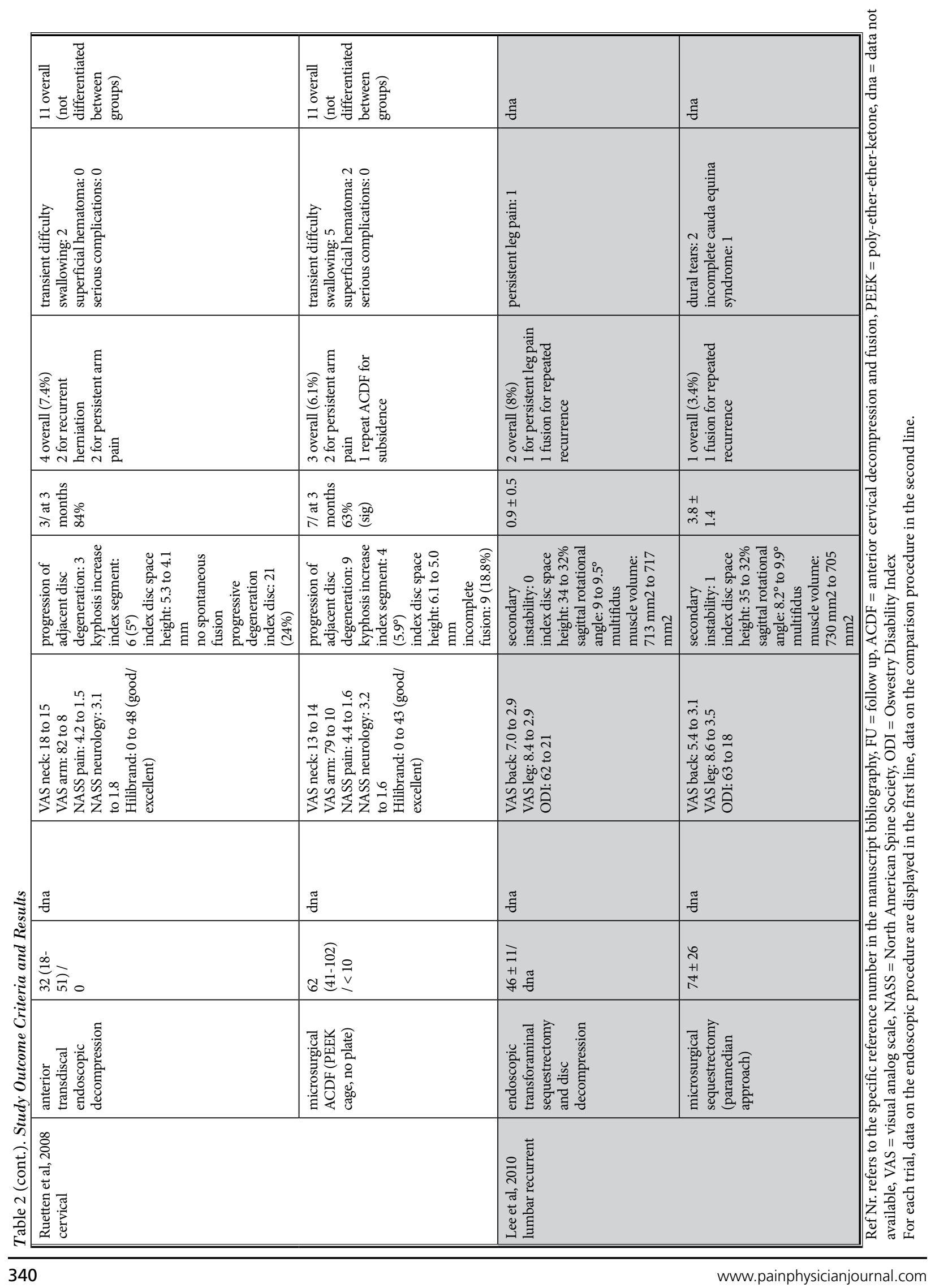


iscectomy) in lumbar disc herniations, irrespective of their location (median, lateral, or extraforaminal). This study was randomized and included 200 patients with a follow-up of 2 years and a follow-up rate of $89 \%$. The key findings were a reduced operating time (22 vs. 43 minutes on average) and a faster return to work (25 vs. 49 days) with the endoscopic technique. Clinical outcome was not significantly different between the techniques, but there were more progressions to fusion and more light complications with the traditional technique.

The third study (31) compared the same techniques as in the second study, but for recurrent lumbar disc herniations after a previous conventional microdiscectomy. This study was randomized and included 100 patients with a follow-up of 2 years and a follow-up rate of $87 \%$. The key findings were a reduced operating time ( 24 vs. 58 minutes on average) and a faster return to work ( 28 vs. 52 days) with the endoscopic technique. Clinical outcome was not significantly different between the techniques, but there were more serious complications with the traditional technique.

The fourth study (32) compared endoscopic anterior (transdiscal) decompression to microsurgical ACDF using a stand-alone PEEK-cage in cervical disc herniations. This study was randomized and included 120 patients with a follow-up of 2 years and a follow-up rate of $86 \%$. The key findings were a reduced operating time (32 vs. 36 minutes on average) and a higher percentage of patents having returned to work after 3 months (84 vs. $63 \%$ ) with the endoscopic technique. Clinical outcome and complication rates were not significantly different between the techniques.

The fifth study (37) compared transforaminal endoscopic lumbar discectomy to lumbar microdiscectomy in recurrent disc herniations. This study had a retrospective, non-randomized design and included 54 patients with an average follow-up of 34 months. The key findings were a reduced operating time (46 vs. 74 minutes on average) and a shorter average stay in hospital (0.9 vs. 3.8 days) with the endoscopic technique. Clinical outcome and complication rates were not significantly different between the techniques.

\section{What are the common findings among these 5 studies?}

All 5 studies demonstrated significant improvement in their clinical target criteria between preoperative and the different time points until final follow-up. No study showed significant differences in these target criteria between the endoscopic technique and the respective standard technique. All 5 studies had significantly shorter operating times for the endoscopic technique compared to the respective standard technique. The reoperation rates were comparable between groups with a possible tendency towards slightly higher reoperation rates with the endoscopic technique in 2 studies $(29,37)$. The radiological target criteria did not show any clinically relevant differences between the endoscopic and the standard technique groups with the exception of one segmental instability in the standard technique group that led to a fusion surgery in the study by Lee et al (37).

\section{What are the differences between the endoscopic and the standard techniques with regards to complications and reoperations?}

In all 5 studies, there were fewer complications reported with the endoscopic techniques compared to the standard techniques. In 2 of the 5 studies, these differences reached statistical significance $(30,31)$. Of these 2 studies, the one on primary lumbar disc herniations showed a higher rate of revision fusion procedures for progressive low back pain (5 vs. one) (30), whereas the study on recurrent lumbar disc herniations showed a difference in serious complications of $21 \%$ vs. $6 \%$, both in favor of the endoscopic approach (31). The study comparing anterior cervical discectomy and fusion (ACDF) to endoscopic anterior transdiscal decompression for cervical disc herniations found less postoperative difficulty with swallowing (5 vs. 2 ) in the endoscopic group without reaching statistical significance (32).

\section{What appear to be the benefits of the endoscopic technique in these $\mathbf{5}$ studies?}

Obvious benefits are shorter operating times and less blood loss (even if not statistically evaluated) in all 5 studies. Three of the 5 studies claim significantly less pain at the surgical site immediately postoperative and less use of pain medication (29-31), but detailed data are not contained in the respective publications. These observations are paralleled by a shorter hospital stay in one (37) and a faster return to work in the 4 other studies (29-32). As described above, there were fewer complications with the endoscopic technique as compared to the standard techniques in all of the 5 studies and lower rates of revision fusion surgeries in one study. 


\section{What were the advantages of the standard technique in these 5 studies?}

The standard techniques appear to have an advantage with regards to the rates of recurrent herniations and repeated recurrent herniations in cervical as well as in lumbar disc surgery, even though statistical significance was not shown in these studies $(29,31,32)$.

\section{What do the radiological target parameters tell us?}

In the 2 trials on cervical disc herniations, radiologically uncertain fusions were observed in almost a fifth of the ACDF cases at 24 months without translating to reduced clinical success, which is not a surprising finding $(29,32)$. A much more interesting observation is that no increased segmental kyphosis was observed after the anterior endoscopic transdiscal approach in the second study when compared to ACDF and that there appeared to be less progression in pre-existing adjacent level disc degeneration with the endoscopic technique (32).

When comparing posterior endoscopic foraminotomy to ACDF, Ruetten et al (29) found a progression in the radiological degeneration of the index disc in $24 \%$ of cases without concomitant progression of segmental kyphosis or creation of new segmental instability. The study by Lee et al (37) showed a pronounced (and statistically significant) decrease in the index disc space height as well as a stronger increase in the sagittal rotational angle when comparing microdiscectomy to a transforaminal endoscopic technique.

\section{Discussion}

The limitations of this review should be examined first. The 5 studies selected by means of our search strategy and exclusion process, while all employing the same full-endoscopic technique, are heterogeneous with regards to spinal region, type of approach and herniation, as well as comparison procedure. It must also be taken into account that the surgeons who performed the RCTs and the CSs evaluated in our review are highly experienced and specialized in the standard techniques as well as in the endoscopic techniques that they studied. The data that found entry into these studies certainly do not originate from the first few hundred cases that these investigators performed. The results obtained in these trials can therefore not be directly translated to what other spinal therapists at an earlier stage of their individual learning curves can expect to achieve.

A second, yet very important, limitation is the fact that all 4 RCTs in this review were performed by the same group of investigators and at the same institution. It will remain to be seen whether other endoscopic spine surgeons in different settings and with a different training background will be able to duplicate these results.

In the context of these limitations, however, our review finds benefits to the patient with these modern, full-endoscopic techniques. Most importantly and at least in the 5 studies that could be considered for this review, these benefits do not appear to come at the cost of increased complication rates or lesser efficacy. Shorter operating times and less postoperative surgical site pain translate to a shorter hospital stay and may lead to a faster return to work.

While the claims of less postsurgical pain with the endoscopic technique made by 3 of the 5 trials (29-31) appear credible based on the access trauma of the comparison procedures, it is a severe shortcoming of these 3 studies that no clear data are contained in the published manuscripts. There was a statistically not significant higher rate of reoperations for recurrence in some of the studies, but a claim that these rates would have become significant with larger numbers is difficult to make at around 100 patients per group. They may however become significant with lesser surgeon experience, which should be considered when extrapolating from these studies to the personal case series and the same is most probably true for complication rates. A solid experience with the standard techniques should therefore remain the basis on which these endoscopic techniques can be mastered step by step.

While this is not uncommon in clinical medicine, it is nevertheless regrettable that with so many publications on endoscopic spine surgery, so few controlled studies are available that compare an established standard procedure to a modern full-endoscopic procedure. Beyond the mere paucity of suitable studies, the fact that most of the available controlled studies originate from one single group of very specialized researchers is a limitation on the generalizability of the clinical results obtained. Having said that and considering the poor quality of data that are the foundation for the establishment of microdiscectomy as the de facto gold standard over open discectomy, the results from the trials discussed here are already a big step in the right direction.

With most of the relevant studies in this field having been published within the past 4 years, there are only few previous reviews on this topic. The most notable one is the paper by Nellensteijn et al (12) submitted in 2009 and published in 2010 . This review, however, is very 
different from ours in a number of respects, some of which have already been mentioned in the introduction. It does not consider cervical disc herniations or other endoscopic approaches other than the lumbar transforaminal approach. The literature search for this review also ends with 2008, so that 3 of the 5 papers that we were able to consider did not find entry into the authors' evaluation. The other review by the same group and also published in 2010 focuses exclusively on transforaminal endoscopic surgery for spinal stenosis, which certainly is not an indication that is frequently treated by means of transforaminal endoscopic techniques (12).

\section{Conclusion}

In summary, there is good quality evidence, but from predominantly only one group, that experienced surgeons can achieve the same clinical results in symptomatic cervical and lumbar disc herniations with full endoscopic procedures as with standard microsurgical procedures.

In experienced hands, these results do not appear to come at the cost of a higher complication rate or more severe complications.

\section{References}

1. Saberski LR. A retrospective analysis of spinal canal endoscopy and laminectomy outcomes data. Pain Physician 2000; 3:193-196.

2. Kambin P. Arthroscopic microdiscectomy. Arthroscopy 1992; 8:287-295.

3. Kovac D. [Automated endoscopic percutaneous diskectomy in the treatment of lumbar disk hernia]. Lijec Vjesn 1991; 113:158-161.

4. Leu H], Schreiber A. [10 years of percutaneous disk surgery: Results and developments]. Schweiz Rundsch Med Prax 1989; 78:1434-1439.

5. Suezawa $Y$, Schreiber A. [Percutaneous nucleotomy with discoscopy. 7 years' experience and results]. Z Orthop Ihre Grenzgeb 1988; 126:1-7.

6. Schreiber A, Suezawa Y. Transdiscoscopic percutaneous nucleotomy in disk herniation. Orthop Rev 1986; 15:35-38.

7. Hausmann B, Forst R. Nucleoscope. Instrumentarium for endoscopy of the intervertebral disc space. Arch Orthop Trauma Surg 1983; 102:57-59.

8. Gibson J, Waddell G. Surgical interventions for lumbar disc prolapse. Spine (Phila Pa 1976). 2007; 32:1735-1747.

9. Osterman H, Seitsalo S, Karppinen J, Malmivaara A. Effectiveness of microdiscectomy for lumbar disc herniation: A randomized controlled trial with 2 years of follow-up. Spine (Phila Pa 1976) 2006; 31:2409-2414.

10. Katayama $\mathrm{Y}$, Matsuyama $\mathrm{Y}$, Yoshihara $\mathrm{H}$, Sakai Y, Nakamura H, Nakashima S, Ito $Z$, Ishiguro N. Comparison of surgical outcomes between macro discectomy and micro discectomy for lumbar disc herniation: A prospective randomized study with surgery performed by the same spine surgeon. Journal of Spinal Disorders and Techniques 2006; 19:344-347.

11. Henriksen L, Schmidt K, Eskesen V, Jantzen $\mathrm{E}$. A controlled study of microsurgical versus standard lumbar discectomy. $\mathrm{Br} J$ Neurosurg 1996; 10:289-293.

12. Nellensteijn J, Ostelo R, Bartels R, Peul W, van Royen B, van Tulder M. Transforaminal endoscopic surgery for symptomatic lumbar disc herniations: A systematic review of the literature. Eur Spine J 2010; 19:181-204.

13. Huang TJ, Hsu RW, Li YY, Cheng CC. Less systemic cytokine response in patients following microendoscopic versus open lumbar discectomy. J Orthop Res 2005; 23:406-411.

14. Schick U, Dohnert J, Richter A, Konig A Vitzthum HE. Microendoscopic lumbar discectomy versus open surgery: an intraoperative EMG study. Eur Spine J 2002; 11:20-26.

15. Arts MP, Brand $R$, van den Akker ME, Koes BW, Bartels RH, Peul WC. Tubular diskectomy vs conventional microdiskectomy for sciatica: A randomized controlled trial. JAMA 2009; 302:149-158.

16. Teli M, Lovi A, Brayda-Bruno M, Zagra A, Corriero A, Giudici F, Minoia L. Higher risk of dural tears and recurrent herniation with lumbar micro-endoscopic discectomy. Eur Spine J 2010; 19:443-450.

17. Manchikanti L, Datta S, Gupta S, Munglani R, Bryce DA, Ward SP, Benyamin RM, Sharma ML, Helm S 2nd, Fellows B, Hirsch JA. A critical review of the American Pain Society Clinical practice guide- lines for interventional techniques: Part 2. Therapeutic interventions. Pain Physician 2010; 13:E215-264.

18. Manchikanti L, Helm S, Singh V, Benyamin RM, Datta S, Hayek SM, Fellows B, Boswell MV. An algorithmic approach for clinical management of chronic spinal pain. Pain Physician 2009; 12:E225-264.

19. Manchikanti L, Singh V, Derby $R$, Schultz DM, Benyamin RM, Prager JP, Hirsch JA. Reassessment of evidence synthesis of occupational medicine practice guidelines for interventional pain management. Pain Physician 2008; 11:393-482.

20. Trescot AM, Chopra P, Abdi S, Datta S, Schultz DM. Systematic review of effectiveness and complications of adhesiolysis in the management of chronic spinal pain: an update. Pain Physician 2007; 10:129-146.

21. Boswell MV, Trescot AM, Datta S, Schultz DM, Hansen HC, Abdi S, Sehgal N, Shah RV, Singh V, Benyamin RM, Patel VB, Buenaventura RM, Colson JD, Cordner HJ, Epter RS, Jasper JF, Dunbar EE, Atluri SL, Bowman RC, Deer TR, Swicegood JR, Staats PS, Smith HS, Burton AW, Kloth DS, Giordano J, Manchikanti L. Interventional techniques: Evidencebased practice guidelines in the management of chronic spinal pain. Pain Physician 2007; 10:7-111.

22. Chopra P, Smith HS, Deer TR, Bowman RC. Role of adhesiolysis in the management of chronic spinal pain: A systematic review of effectiveness and complications. Pain Physician 2005; 8:87-100.

23. Boswell MV, Shah RV, Everett CR, Se- 
hgal N, McKenzie Brown AM, Abdi S, Bowman RC 2nd, Deer TR, Datta $S$, Colson JD, Spillane WF, Smith HS, Lucas LF, Burton AW, Chopra P, Staats PS, Wasserman RA, Manchikanti L. Interventional techniques in the management of chronic spinal pain: Evidencebased practice guidelines. Pain Physician 2005; 8:1-47.

24. Helm S 2nd, Gross JD, Varley KG. Minisurgical approach for spinal endoscopy in the presence of stenosis of the sacral hiatus. Pain Physician 2004; 7:323-325.

25. Manchikanti L, Rivera JJ, Pampati V, Damron KS, Beyer CD, Brandon DE, Wilson SR. Spinal endoscopic adhesiolysis in the management of chronic low back pain: A preliminary report of a randomized, double-blind trial. Pain Physician 2003; 6:259-267.

26. Hoogland T, Schubert M, Miklitz B, Ramirez A. Transforaminal posterolateral endoscopic discectomy with or without the combination of a low-dose chymopapain: A prospective randomized study in 280 consecutive cases. Spine (Phila Pa 1976) 2006; 31:E890-897.

27. Huang TJ, Li YY, Weng YJ, Cheng CC, Hsu RWW. Interleukin-6 protein expression is more important than interleukin-6 mRNA levels in assessing surgical invasiveness. Journal of Surgical Research 2007; 142:53-58.

28. Righesso O, Falavigna A, Avanzi O. Comparison of open discectomy with microendoscopic discectomy in lumbar disc herniations: Results of a randomized controlled trial. Neurosurgery 2007; 61:545-549; discussion 549.

29. Ruetten S, Komp M, Merk H, Godolias G. Full-endoscopic cervical posterior foraminotomy for the operation of lateral disc herniations using $5.9-\mathrm{mm}$ endoscopes: A prospective, randomized, controlled study. Spine (Phila Pa 1976) 2008; 33:940-948.

30. Ruetten S, Komp M, Merk H, Godolias G. Full-endoscopic interlaminar and transforaminal lumbar discectomy ver- sus conventional microsurgical technique: A prospective, randomized, controlled study. Spine (Phila Pa 1976) 2008; 33:931-939.

31. Ruetten S, Komp M, Merk H, Godolias $G$. Recurrent lumbar disc herniation after conventional discectomy: A prospective, randomized study comparing full-endoscopic interlaminar and transforaminal versus microsurgical revision. J Spinal Disord Tech 2009; 22:122-129.

32. Ruetten S, Komp M, Merk H, Godolias G. Full-endoscopic anterior decompression versus conventional anterior decompression and fusion in cervical disc herniations. Int Orthop 2009; 33:1677-1682.

33. Akshulakov SK, Kerimbaev TT, Sekenova GT, Makimova GS. [Analysis of the results of endoscopic surgical treatment for hernias of the lumbosacral disks]. Zh Vopr Neirokhir Im N N Burdenko 2005; 4:18-21; discussion 22.

34. Chao Z, Yue Z, Tong-wei C, Jian W, Yong $\mathrm{H}$, Yong $\mathrm{P}$. Microendoscopic discectomy, a less traumatic procedure for lumbar disk herniation. Chin J Traumatol 2007; 10:311-314.

35. Kang Y, Endo K. Sagittal spinal alignment in patients with lumbar disc herniation after endoscopic discectomy. [Japanese]. Journal of Tokyo Medical University 2009; 67:431-438.

36. Lee DY, Lee SH. Learning curve for percutaneous endoscopic lumbar discectomy. Neurol Med Chir (Tokyo) 2008; 48:383-388; discussion 388-389.

37. Lee DY, Shim CS, Ahn Y, Choi YG, Kim $\mathrm{HJ}$, Lee SH. Comparison of percutaneous endoscopic lumbar discectomy and open lumbar microdiscectomy for recurrent disc herniation. J Korean Neurosurg Soc 2009; 46:515-521.

38. Liu WG, Wu XT, Min J, Guo JH, Zhuang SY, Chen XH, Deng G, He SC, Fang W, Zhu GY, Teng G]. [Long-term outcomes of percutaneous lumbar discectomy and microendoscopic discectomy for lumbar disc herniation]. Zhonghua Yi Xue Za Zh
2009; 89:750-753.

39. Mayer HM, Brock M. Percutaneous endoscopic discectomy: Surgical technique and preliminary results compared to microsurgical discectomy. J Neurosurg 1993; 78:216-225.

40. Sasaoka R, Nakamura $H$, Konishi $S$, Nagayama R, Suzuki E, Terai H, Takaoka K. Objective assessment of reduced invasiveness in MED: Compared with conventional one-level laminotomy. European Spine Journal 2006; 15:577-582.

41. Shin DA, Kim KN, Shin HC, Yoon do H. The efficacy of microendoscopic discectomy in reducing iatrogenic muscle injury. J Neurosurg Spine 2008; 8:39-43.

42. Toyone T, Tanaka T, Kato D, Kaneyama R. Low-back pain following surgery for lumbar disc herniation: A prospective study. Journal of Bone and Joint Surgery Series A 2004; 86:893-896.

43. Xiao LZ, Zhang DR, Jiang J. A comparative study about curative effect of two different therapies to the lumbar disc herniation. [Chinese]. Chinese Journal of Clinical Rehabilitation 2002; 6:552-553.

44. Yang SC, Fu TS, Chen LH, Chen WJ, Tu YK. Identifying pathogens of spondylodiscitis: Percutaneous endoscopy or CTguided biopsy. Clinical Orthopaedics and Related Research 2008; 466:3086-3092.

45. Zhang C, Zhou Y, Chu TW, Wang J, Hao Y, Pan Y. Microendoscopic discectomy, a less traumatic procedure for lumbar disk herniation. Chinese Journal of Traumatology - English Edition 2007; 10:311-314.

46. Zhang C, Zhou Y, Chu TW, Wang J, Wang WD, Hao Y. [Traumatic responses following microendoscopic discectomy: clinical analysis of 44 patients]. Zhonghua Yi Xue Za Zhi 2006; 86:3039-3042.

47. Zhou Y, Zhang C, Wang J, Chu TW, Li $\mathrm{CQ}$, Zhang ZF, Zheng WJ. Minimally invasive strategies and options for farlateral lumbar disc herniation. Chin J Traumatol 2008; 11:259-266. 